\title{
Short communication: Growth of dairy isolates of Geobacillus thermoglucosidans in skim milk depends on lactose degradation products supplied by Anoxybacillus flavithermus as secondary species
}

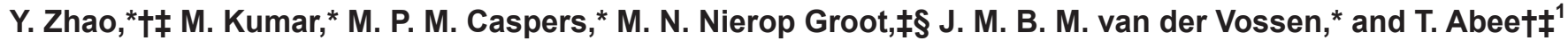 \\ *TNO Microbiology and Systems Biology, Postbus 360, 3700 AJ Zeist, the Netherlands \\ †Laboratory of Food Microbiology, PO Box 17, 6700 AA Wageningen, the Netherlands \\ $\ddagger$ Top Institute Food and Nutrition, PO Box 557, 6700 AN Wageningen, the Netherlands \\ §Wageningen Food and Biobased Research, PO Box 17, 6700 AA Wageningen, the Netherlands
}

\section{ABSTRACT}

Thermophilic bacilli such as Anoxybacillus and Geobacillus are important contaminants in dairy powder products. Remarkably, one of the common contaminants, Geobacillus thermoglucosidans, showed poor growth in skim milk, whereas significant growth of $G$. thermoglucosidans was observed in the presence of an Anoxybacillus flavithermus dairy isolate. In the present study, we investigated the underlying reason for this growth dependence of $G$. thermoglucosidans. Wholegenome sequences of $4 \mathrm{~A}$. flavithermus strains and $4 \mathrm{G}$. thermoglucosidans strains were acquired, with special attention given to carbohydrate utilization clusters and proteolytic enzymes. Focusing on traits relevant for dairy environments, comparative genomic analysis revealed that all $G$. thermoglucosidans strains lacked the genes necessary for lactose transport and metabolism, showed poor growth in skim milk, and produced white colonies on X-gal plates, indicating the lack of $\beta$-galactosidase activity. The $A$. flavithermus isolates scored positive in these tests, consistent with the presence of a putative lactose utilization gene cluster. All tested isolates from both species showed proteolytic activity on milk plate count agar plates. Adding glucose or galactose to liquid skim milk supported growth of $G$. thermoglucosidans isolates, in line with the presence of the respective monosaccharide utilization gene clusters in the genomes. Analysis by HPLC of A. flavithermus TNO-09.006 culture filtrate indicated that the previously described growth dependence of G. thermoglucosidans in skim milk was based on the supply of glucose and galactose by $A$. flavithermus TNO-09.006.

Key words: thermoresistant spore, thermophile, symbiosis

Received June 21, 2017.

Accepted September 20, 2017.

${ }^{1}$ Corresponding author: tjakko.abee@wur.nl

\section{Short Communication}

Heat-resistant spores from thermophilic bacilli are a major concern in dairy powder processing facilities, posing a risk for product contamination. This group of bacteria is able to grow in areas of skim milk manufacturing plants, such as heat exchangers and evaporation sections, where elevated temperatures, typically between $40^{\circ} \mathrm{C}$ to $65^{\circ} \mathrm{C}$, are applied (Seale et al., 2015). Although these bacilli are not pathogenic, their presence as spores in end products may lead to quality issues in the respective reconstituted products when conditions are favorable for germination and outgrowth (Setlow and Johnson, 2013; Watterson et al., 2014; Wells-Bennik et al., 2016). Obviously, such quality issues could also lead to severe economic losses.

Spore-forming bacteria survive through their innate ability to resist adverse conditions in dairy manufacturing processes, including heat, mechanical disruption, and a wide variety of chemicals (Burgess et al., 2010). Moreover, both spores and vegetative cells can attach to stainless steel and fouled surfaces in dairy processing lines. Once attached to the surface, the spores may germinate, grow out, and form biofilms. Spores from thermophilic bacilli detected in end products might originate from biofilms formed in dairy processing lines (Seale et al., 2015). Thermophilic bacteria generally have a high growth rate with generation times typically in the range of 15 to 20 min under optimal conditions. Thus, high cell counts can be reached in a short period. Additionally, the resistance of the endospores to heat and chemicals makes it difficult to fully eliminate thermophilic bacteria from dairy processing environments (Burgess et al., 2010; Wells-Bennik et al., 2016). Understanding the proliferation and survival of spore-forming bacteria within dairy processing environments and dairy products is therefore a prerequisite to develop effective methods to control and reduce contamination.

Thermophilic bacteria predominantly isolated from the dairy processing industry are of the species $A n$ - 
oxybacillus flavithermus and the genus Geobacillus spp., formerly classified as Bacillus (Burgess et al., 2010; Zhao et al., 2013; Sadiq et al., 2016). Anoxybacillus flavithermus typically dominate the preheating section of the skim milk powder process, whereas a mix of A. flavithermus and Geobacillus spp. is found in the evaporation and drying stages of the process. Geobacillus spp. are predominantly isolated from fouling sites (Zhao et al., 2013).

To proliferate in skim milk, bacteria must utilize carbon and nitrogen sources in skim milk. Raw milk is a nutrient-rich source supporting bacterial growth. It contains approximately $3.4 \%$ protein, $3.7 \%$ fat, $4.6 \%$ lactose, and $0.7 \%$ ash by weight (Jensen, 1995). However, G. thermoglucosidans strains TNO-09.020 and TNO-09.023, previously isolated from a fouling site in the dairy processing pipeline, showed poor growth on skim milk plates and in liquid skim milk. This growth deficiency and their biofilm-forming capacity in skim milk were restored when A. flavithermus, a proteolytic thermophilic sporeformer from the microbiota of the same dairy concentrate processing plant, was added as a secondary species (Zhao et al., 2013). To understand the mechanism of growth dependence of $G$. thermoglucosidans on the presence of $A$. flavithermus as secondary species in skim milk, we performed a comparative genomic analysis on isolates of both species. In addition to the 5 dairy isolates (Anoxybacillus flavithermus TNO-09.006, TNO-09.014, TNO-09.016; Geobacillus thermoglucosidans TNO-09.020, TNO-09.023), 1 A. flavithermus and 2 G. thermoglucosidans hot spring isolates (Anoxybacillus flavithermus WK1, Geobacillus thermoglucosidans C56-YS93, Geobacillus thermoglucosidans Y4-1MC1) available in public genome databases were included in the current study (Table 1). Particularly, the presence and absence of genes involved in metabolic pathways including nitrogen (proteolytic system) and carbohydrate metabolism, required for growth in skim milk, were taken into consideration. Genes present in only 1 of the 2 species were enumerated and their annotated function was inspected for possible roles in growth in skim milk. Moreover, growth experiments in skim milk without and with added supplements that could conceivably support the outgrowth of $G$. thermoglucosidans were conducted. Finally, the cell-free culture filtrate of $A$. flavithermus was analyzed to identify compounds produced by this organism that could support the growth of $G$. thermoglucosidans in skim milk.

The genomes of the 8 thermophilic bacilli of the species $G$. thermoglucosidans and A. flavithermus (Table 1) were compared with each other and to the reference nonthermophilic strain Bacillus subtilis 168. For the newly sequenced genomes from this study (Zhao et al., 2012; Caspers et al., 2013, 2016), after assem-

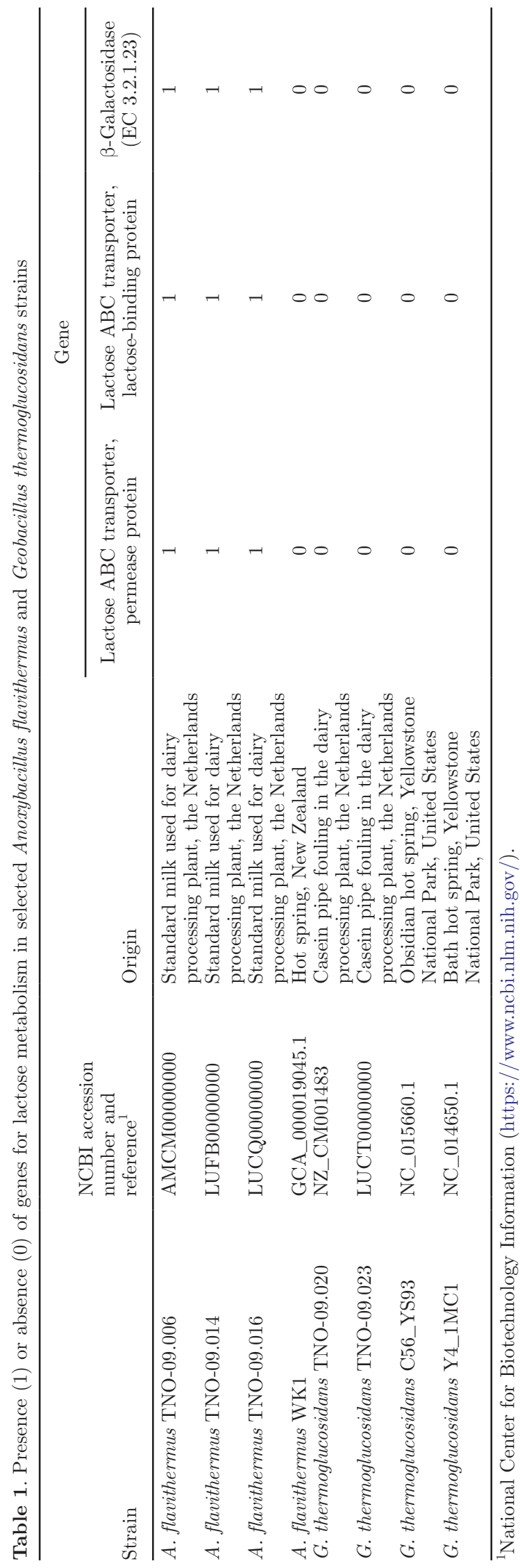


bly of sequence reads into contigs, RAST (Aziz et al., 2008) was used to predict open reading frames and to conduct automatic annotation. Selected genes and protein sequences were manually curated using BLASTP (Altschul et al., 1990) and InterPro (Mitchell et al., 2015). Orthologous groups (i.e., gene families) in the 8 genomes were determined using OrthoMCL (Enright et al., 2002). This program uses all-against-all protein BLAST, where it groups proteins with greater homology within the species than proteins homologous to proteins outside the species. In this way, orthologs (genes in different species that evolved from a common ancestral gene by speciation) are separated from paralogs (genes related by duplication within a genome). When an orthologous group contained more than 1 gene per strain (i.e., highly similar genes), the group was manually split into separate orthologous groups containing only 1 gene per strain. An exception was made for transposons and other mobile elements.

The strains used in this study were obtained from $-80^{\circ} \mathrm{C}$ stocks. Tryptone soy agar (plates) and tryptone soy broth (Tritium Microbiologie, Eindhoven, the Netherlands) were used as basic culture media. Inocula used in this study were overnight cultures with optical density standardized to 1 and measured at a wavelength of $600 \mathrm{~nm}$ using a spectrophotometer (Ultrospec 2100, Amersham Bioscience, Little Chalfont, UK). Inoculum density used in the growth experiments was $1 \%$ ( $\mathrm{vol} / \mathrm{vol}$ ). All experiments throughout this study were performed as multiple independent duplicates or triplicates.

Skim milk agar plates for comparative growth tests contained $50 \%$ (vol/vol) UHT skim milk (0\% fat, FrieslandCampina, Amersfoort, the Netherlands), $1.5 \%$ agarose, and distilled water. After mixing the ingredients, the medium was subsequently autoclaved at $20 \mathrm{~min}$ for $121^{\circ} \mathrm{C}$. Lactose-free milk plates were made as described above, but using lactose-free milk (Konings Zuivel B.V., Bergambacht, the Netherlands) instead of UHT skim milk. Milk plate count agar (MPCA) plates contained tryptone $(0.13 \mathrm{~g} / \mathrm{L})$, yeast extract $(2.7 \mathrm{~g} / \mathrm{L})$, glucose $(1.1 \mathrm{~g} / \mathrm{L})$, skim milk powder $(1.1 \mathrm{~g} / \mathrm{L})$, and agar $(33.3 \mathrm{~g} / \mathrm{L})$, and plates with a final concentration of $40 \mu \mathrm{g} / \mathrm{mL} 5$-bromo-4-chloro3 -indolyl- $\beta$-D-galactopyranoside (X-gal) were made as described previously (Zhao et al., 2013). Overnight cultures (optical density $=1$ ) of the 8 selected strains were streaked separately to acquire single colonies on the prepared plates; subsequently, the plates were incubated overnight at $55^{\circ} \mathrm{C}$ for further observation. Growth experiments in liquid skim milk without and with added supplements were performed using the following procedures. D-Glucose or D-galactose (both from Tritium Microbiologie) were added at $0.25 \mathrm{~g} / \mathrm{L}$ to freshly obtained UHT skim milk for the growth assays; and lactose-free milk with $2.5 \mathrm{~g} / \mathrm{L}$ glucose or galactose was used directly for this experiment. These milk media were subsequently inoculated with $A$. flavithermus or $G$. thermoglucosidans and incubated for up to 24 $\mathrm{h}$ at $65^{\circ} \mathrm{C}, 100 \mathrm{rpm}$ of orbital shaking. Selected time samples were subsequently diluted and spread plated on tryptone soy agar plates for enumeration. The $\mathrm{pH}$ of the cultures was measured using a $\mathrm{pH}$ meter (Mettler Toledo, Greifensee, Switzerland).

Finally, to study the effect of cell-free culture supernatants of $A$. flavithermus on growth of $G$. thermoglucosidans in skim milk, cell-free culture supernatants of 24-h cultures of $A$. flavithermus in skim milk medium were prepared. The $\mathrm{pH}$ of the cultures ( $\mathrm{pH} 5.9$ ) was set to $\mathrm{pH} 4.7$ using $4 \mathrm{~N} \mathrm{HCl}$ to precipitate milk caseins and subsequently filtered using a $0.45-\mu \mathrm{m}$ filter (Millipore, Merck, Billerica, MA). The filtrate was centrifuged (Allegra bench top centrifuge, Beckman Counter, Brea, CA) at 4,000 $\times g$ for $10 \mathrm{~min}$. The clear supernatant was collected and the $\mathrm{pH}$ of the supernatant was adjusted to the initial pH 5.9 using $4 \mathrm{~N} \mathrm{NaOH}$ and stored at $-20^{\circ} \mathrm{C}$ for later use. The filtrates of the 24-h A. flavithermus cultures in skim milk were added to skim milk at a ratio of 2:1 to assess the effect on growth of G. thermoglucosidans. These filtrates were also subjected to HPLC assays to quantify sugars and organic acids present in cell-free culture filtrates of A. flavithermus TNO-09.006. The HPLC was performed using an Aminex HPX-87H column (BioRad Laboratories, Hercules, CA) mounted in an Alliance e2695 HPLC apparatus (Waters, Milford, MA). The column was eluted with $0.6 \mathrm{~mL} / \mathrm{min} 5$ $\mathrm{mM} \mathrm{H}_{2} \mathrm{SO}_{4}$ at $60^{\circ} \mathrm{C}$. Peaks were detected by a refractive index detector and a dual-wavelength absorbance detector at 210 and $270 \mathrm{~nm}$. Raw data were processed into peak areas, and concentrations were calculated using Waters Empower 2 software (Waters).

Comparative genomics revealed that genomes of $A$. flavithermus strains (except for A. flavithermus WK1 isolated from a hot spring) encompassed genes encoding a lactose $\mathrm{ABC}$ transporter cassette and $\beta$-galactosidase activity that are involved in the uptake and the utilization of lactose (de Vos and Vaughan, 1994); these genes were lacking in the G. thermoglucosidans genomes. Because $G$. thermoglucosidans lacks these genes, it might be unable to utilize lactose present in skim milk for its activity and growth. Notably, genome analysis revealed all strains to contain an extensive repertoire of proteolytic enzymes, including genes encoding putative proteases and peptidases (Y. Zhao, unpublished data). This would suggest that acquisition of nitrogen sources by $G$. thermoglucosidans is not a limiting factor for 
Table 2. Growth of Anoxybacillus flavithermus and Geobacillus thermoglucosidans strains on skim milk plates, in liquid skim milk, on X-gal plates, and on $1 \%$ milk plate count agar (MPCA) plates

\begin{tabular}{|c|c|c|c|c|c|}
\hline Strain & $\begin{array}{l}\text { On skim } \\
\text { milk agar plate }{ }^{1}\end{array}$ & \multicolumn{2}{|c|}{ Cell count (log cfu/mL) } & $\begin{array}{l}\text { On MPCA } \\
(\text { halo) }\end{array}$ & $\begin{array}{l}\text { On X-gal } \\
\text { plate }^{3}\end{array}$ \\
\hline A. flavithermus TNO-09.016 & + & $3.7( \pm 0.5)$ & $7.7( \pm 0.2)$ & + & Blue \\
\hline A. flavithermus WK1 & - & $3.7( \pm 0.2)$ & $4.0( \pm 1.0)$ & + & White \\
\hline G. thermoglucosidans TNO-09.020 & - & $3.8( \pm 0.2)$ & $4.4( \pm 0.5)$ & ++ & White \\
\hline G. thermoglucosidans Y4_1MC1 & - & $4.4( \pm 0.5)$ & $5.8( \pm 1.6)$ & ++ & White \\
\hline
\end{tabular}

${ }^{1}$ Where $-=$ no visible colony; $+=$ visible colonies detected.

${ }^{2}$ Where $-=$ no halo; $+=$ weak halo; $++=$ large halo around the colony on MPCA plates indicative of proteolytic activity.

${ }^{3}$ Blue colony on X-gal (5-bromo-4-chloro-3-indolyl- $\beta$-D-galactopyranoside) plates $=$ positive for $\beta$-galactosidase activity, white colony $=$ negative for $\beta$-galactosidase activity.

growth in skim milk, as previously suggested (Zhao et al., 2013). Based on this genome analysis, we hypothesized that $G$. thermoglucosidans strains cannot utilize lactose present in skim milk and cannot grow readily in skim milk where lactose is the sole energy source for the initiation of growth, whereas A. flavithermus strains, except for strain WK1, are able to do so because they are equipped with the genes involved in the uptake and utilization of lactose.

We subsequently validated this hypothesis by combining comparative genome analysis with results obtained from growth experiments on X-gal plates and skim milk plates, in liquid skim milk, and on 1\% MPCA plates. All colonies of $G$. thermoglucosidans strains on X-gal plates appeared white, indicating the lack of $\beta$-galactosidase activity, whereas all $A$. flavithermus strains except WK1 produced blue colonies, indicating hydrolysis of X-gal resulting from $\beta$-galactosidase activity (Table 2 ). This phenotypic result matches our prediction based on the comparative genome analysis. Additionally, we determined the growth capacity of the G. thermoglucosidans and $A$. flavithermus strains on skim milk plates and in liquid skim milk. All A. flavithermus strains except WK1 could form visible colonies on skim milk plates, whereas tested $G$. thermoglucosidans strains (and $A$. flavithermus WK1) did not show visible growth on skim milk plates. Growth assays in liquid milk with $A$. flavithermus and G. thermoglucosidans strains showed the same trend as growth on skim milk plates (Table 1). All A. flavithermus strains except WK1 were able to grow and reached cell densities of 7.5 to $7.7 \mathrm{log} \mathrm{cfu} /$ $\mathrm{mL}$ within $6 \mathrm{~h}$ in skim milk, whereas counts of the G. thermoglucosidans strains and A. flavithermus WK1 remained close to the inoculation cell density after $6 \mathrm{~h}$. Thus, the presence of genes encoding $\beta$-galactosidase activity and a lactose $\mathrm{ABC}$ transporter cassette in these thermophilic bacilli correlated with their capacity to grow rapidly in skim milk, which points to an essential and differentiating role of the identified putative lactose utilization cluster in these strains. Notably, all tested isolates from both species showed proteolytic activity on MPCA plates (Table 2). This indicates that the inability of $G$. thermoglucosidans to grow in skim milk is not due to the lack of proteolytic digestion of milk proteins. Thus, we hypothesized that the inability to digest lactose and, therefore, no access to monosaccharides (glucose and galactose) as the lactose hydrolyzing products, is a limiting factor for rapid growth of G. thermoglucosidans strains in milk.

To test and confirm the hypothesis that only lactose uptake and hydrolyzing capacity were impaired, we conducted growth assays with $G$. thermoglucosidans in skim milk without and with supplementation of glucose or galactose, as well as in an assay with lactose-free milk; that is, milk in which the lactose was hydrolyzed by lactase, resulting in available glucose and galactose (Figure 1). Geobacillus thermoglucosidans exhibited limited growth in skim milk, having approximately 0.5and 0.8-log-unit increases in viable counts in 6 and 24 $\mathrm{h}$, respectively (Figure 1A). The presence of glucose, galactose, and hydrolyzed lactose (glucose and galactose) enhanced growth of $G$. thermoglucosidans, resulting in a $\sim 2$-log-unit increase within $6 \mathrm{~h}$ (Figure 1B to D). The fact that glucose and galactose supported growth in skim milk of $G$. thermoglucosidans suggests that in a co-culture, hydrolysis of lactose by $A$. flavithermus may supply glucose, galactose, or both to $G$. thermoglucosidans, supporting its growth in skim milk. We therefore analyzed the sugars and organic acids present in cell-free culture filtrates of $A$. flavithermus TNO-09.006 and G. thermoglucosidans TNO-09.020 grown in skim milk by using HPLC, which confirmed that lactose is degraded by $A$. flavithermus, and that residual levels of glucose and galactose were present. 
Additionally, $\beta$-galactosidase activity was detected in the cell-free culture filtrate harvested after $24 \mathrm{~h}$ of growth of $A$. flavithermus in skim milk at $55^{\circ} \mathrm{C}$ (Y. Zhao, unpublished data). Subsequent studies in skim milk with added $A$. flavithermus TNO-09.006 culture filtrates showed stimulation of growth of $G$. thermoglucosidans TNO-09.020 (Figure 2). These experiments support the hypothesis that the observed growth stimulation of $G$. thermoglucosidans can be attributed to supply of lactose degradation products via $\beta$-galactosidase activity of $A$. flavithermus TNO-09.006.

Notably, when G. thermoglucosidans was grown in skim milk with addition of glucose, viable counts after first growing for $6 \mathrm{~h}$ subsequently declined by almost 3 $\log$ units after $24 \mathrm{~h}$ (Figure 1B). A significant decrease in the $\mathrm{pH}$ value to 5.4 in this $G$. thermoglucosidans culture was also observed (Figure 1B). This acidification would explain the decrease in viability of the $G$. thermoglucosidans cells. Previous studies have reported the limited capacity of thermophilic bacilli to cope with low $\mathrm{pH}$ conditions where relatively high minimum $\mathrm{pH}$ values (around $\mathrm{pH} 6$ ) for growth were documented (Tola and Ramaswamy, 2014). Notably, G. thermoglucosidans also showed efficient growth in the lactose-free (glucose- and galactose-containing) milk, similarly followed by a decline in cell numbers at $24 \mathrm{~h}$, correlating with a significant decline in $\mathrm{pH}$ (Figure 1D). In contrast, in skim milk with supplementation of galactose, growth of $G$. thermoglucosidans was comparable to that in medium with glucose added and lactose-free milk but no significant decrease of cell density was observed at 24 $\mathrm{h}$. In line with this finding, the decline in $\mathrm{pH}$ was also less severe (Figure 1C). Except for growth in skim milk (Figure 1E), similar growth and acidification behavior was observed for $A$. flavithermus (Figure $1 \mathrm{~F}$ to $\mathrm{H}$ ).

Besides monitoring colony-forming units and $\mathrm{pH}$ change during growth, we also monitored spore counts at different time points. Notably, we could not visually detect spores using qualitative microscopy in samples from $G$. thermoglucosidans and A. flavithermus cultures in skim milk or in skim milk supplemented with glucose and lactose-free milk (hydrolyzed lactose). Nevertheless, we did observe spores of $G$. thermoglucosidans and A. flavithermus after growth in galactose-supplemented skim milk (final $\mathrm{pH}$ of 6 ). The above observation, combined with the extensive decrease in $\mathrm{pH}$ of the growth medium observed only in skim milk supplemented with glucose or in glucose-containing lactose-free skim milk, suggests that rapid acidification of the growth medium inhibits sporulation of $G$. thermoglucosidans and A. flavithermus. The negative influence of low $\mathrm{pH}$ on sporulation was also described by Yazdany and Lashkari (1975). In their study, Geobacillus stearother- mophilus ATCC 7953 and G. stearothermophilus NCIB 8919 produced few spores when cultured in a medium with final $\mathrm{pH}$ around 5.5, whereas sporulation of $G$. stearothermophilus occurred in a medium adjusted to pH 7.7 to 8.7 (Yazdany and Lashkari, 1975). It is conceivable that glucose metabolism-induced acidification leads to a reduction in the total count (cfu), preventing the formation of spores. Factors that contribute to the relatively high minimum $\mathrm{pH}$ for growth of a range of thermophilic sporeformers and the loss of sporulation capacity under weak acidic conditions remain to be elucidated.

In conclusion, this study indicated that the previously described growth stimulation of $G$. thermoglucosidans during co-culture in skim milk with $A$. flavithermus TNO-09.006 is not based on proteolytic activity of the latter, but rather is due to the supply of glucose and galactose following lactose degradation by $\beta$-galactosidase of $A$. flavithermus TNO-09.006. In addition, we observed that glucose metabolism-induced acidification in skim milk led to a reduction in total count in the late growth stage of $A$. flavithermus and $G$. thermoglucosidans and, in turn, hampered sporulation. These observations shed new insights into the interrelationship within microbiological communities of dairy sporeformers and could have implications for industrial hygiene operations. Future studies will be directed at studying whether these observations in A. flavithermus and $G$. thermoglucosidans hold true for other known dairy or nondairy thermophilic spore-forming species such as G. stearothermophilus. The latter suggestion is based on a recent paper by Burgess et al. (2017) that provided novel insights in diversity of $G$. stearothermophilus strains and presented genotypic and phenotypic evidences for lactose utilization capacity in dairy strains of this species. Greater understanding of those thermophilic sporeformers is needed to develop better control measures in milk processing environments.

\section{ACKNOWLEDGMENTS}

We thank Lars Wilms (TNO, Zeist, the Netherlands) for assisting in conducting filtrate experiments, Karin Overkamp (TNO) for assisting HPLC experiments, and Roland Siezen (CMBi, Nÿmegen, the Netherlands) for bio-IT support. The project is funded by TI Food and Nutrition (Wageningen, the Netherlands), a publicprivate partnership on precompetitive research in food and nutrition. The public partners are responsible for the study design, data collection, and analysis, decision to publish, and preparation of the manuscript. The private partners have contributed to the project through regular discussion. 

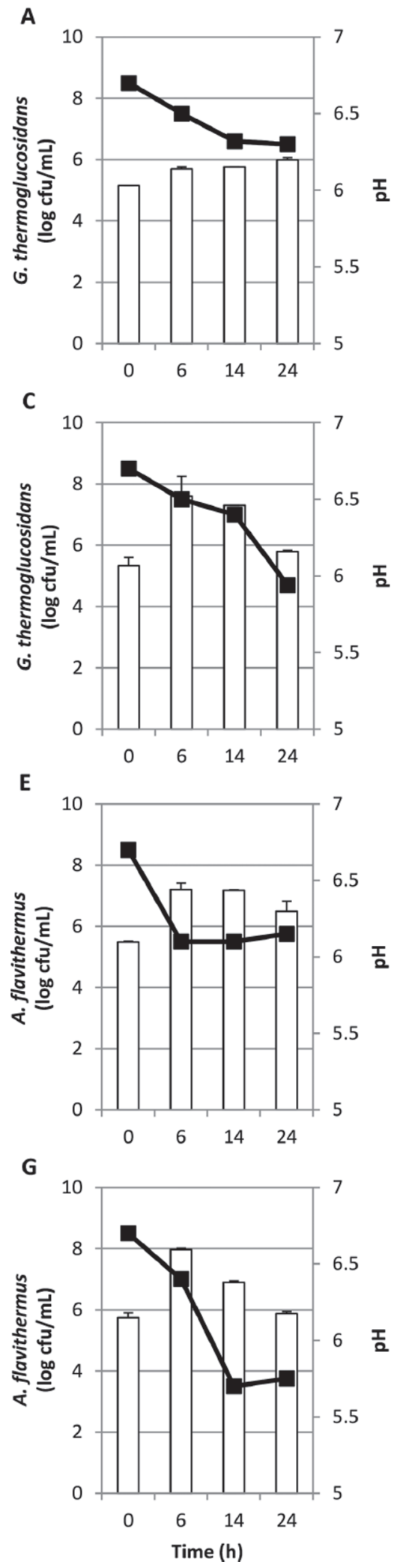

B

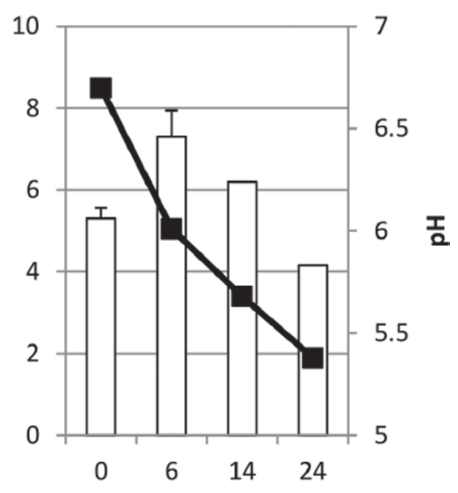

D

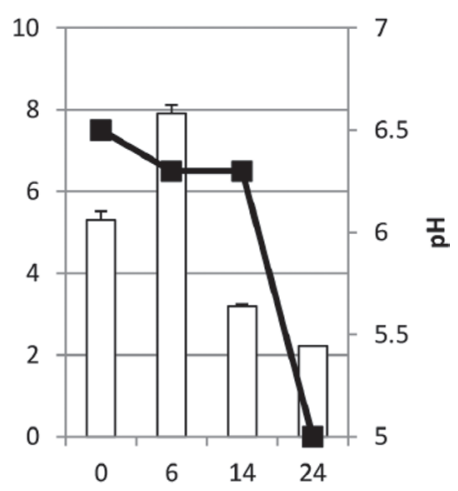

$\mathbf{F}$

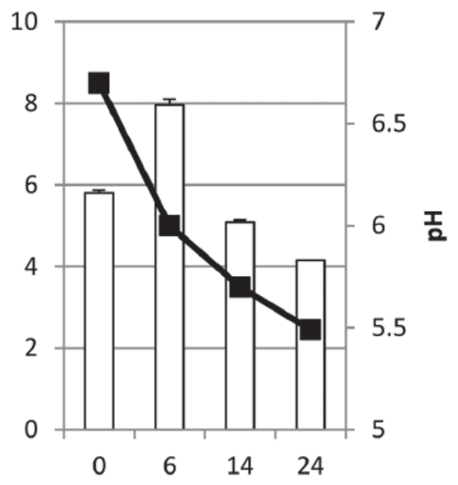

H

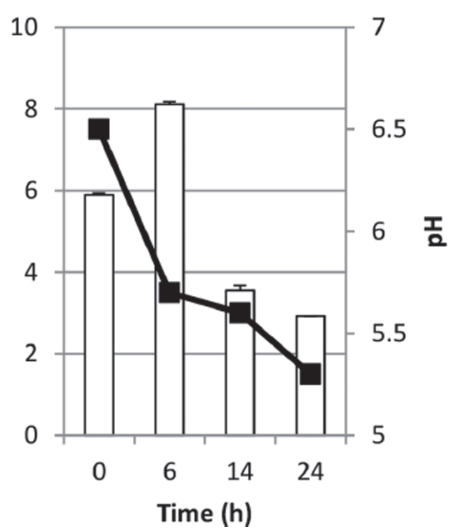

Figure 1. Growth of Geobacillus thermoglucosidans TNO-09.020 (panels A to D) and Anoxybacillus flavithermus TNO-09.006 (panels E to H) in skim milk without and with supplements, and in lactose-free milk: (A, E) skim milk; (B, F) skim milk + 0.25\% glucose; (C, G) skim milk + $0.25 \%$ galactose; and $(\mathrm{D}, \mathrm{H})$ lactose-free (lactase-treated) milk containing $2.5 \%$ glucose and $2.5 \%$ galactose. Total counts (log cfu/mL) are shown in bar graphs and $\mathrm{pH}$ measurements in filled squares. Error bars represent standard deviations of biological duplicates. 
A

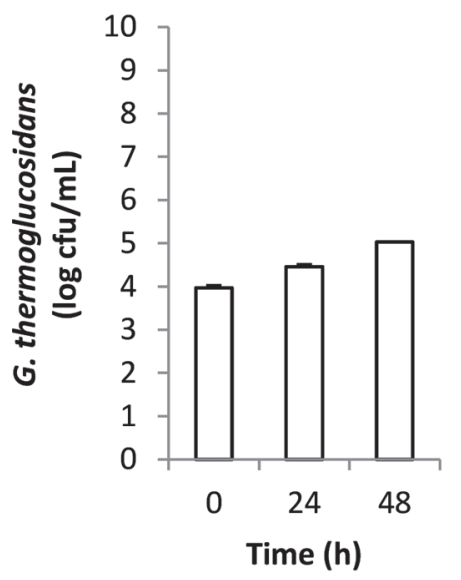

B

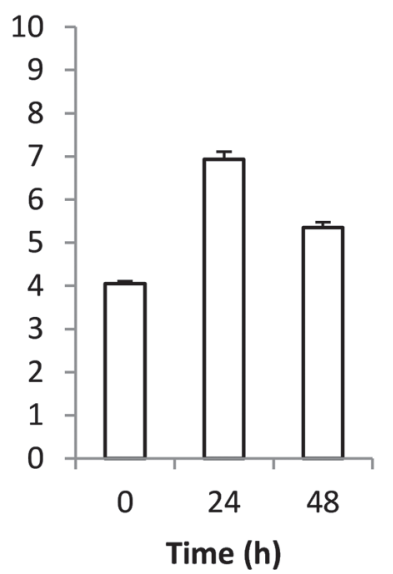

C

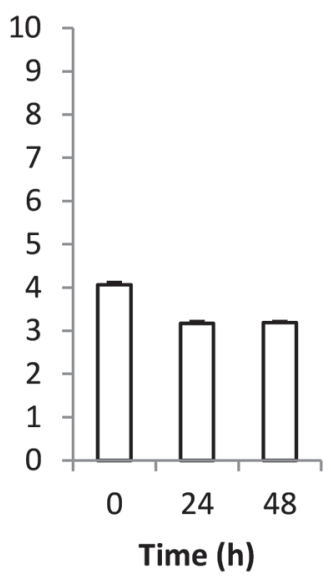

Figure 2. Effect of Anoxybacillus flavithermus TNO-09.006 cell-free culture filtrate (filtrate) on the growth of Geobacillus thermoglucosidans TNO-09.020 at the indicated sample times in (A) skim milk; (B) skim milk with added filtrate; and (C) filtrate only. Error bars represent standard deviations of biological duplicates.

\section{REFERENCES}

Altschul, S. F., W. Gish, W. Miller, E. W. Myers, and D. J. Lipman. 1990. Basic alignment search tool. J. Mol. Biol. 215:407-410.

Aziz, R. K., D. Bartels, A. A. Best, M. DeJongh, T. Disz, R. A. Edwards, K. Formsma, S. Gerdes, E. M. Glass, M. Kubal, F. Meyer, G. J. Olsen, R. Olson, A. L. Osterman, R. A. Overbeek, L. K. McNeil, D. Paarmann, T. Paczian, B. Parrello, G. D. Pusch, C. Reich, R. Stevens, O. Vassieva, V. Vonstein, A. Wilke, and O. Zagnitko. 2008. The RAST server: Rapid annotations using subsystems technology. BMC Genomics 9:75.

Burgess, S. A., S. H. Flint, D. Lindsay, M. P. Cox, and P. J. Biggs. 2017. Insights into the Geobacillus stearothermophilus species based on phylogenomic principles. BMC Microbiol. 17:140.

Burgess, S. A., D. Lindsay, and S. H. Flint. 2010. Thermophilic bacilli and their importance in dairy processing. Int. J. Food Microbiol. 144:215-225.

Caspers, M. P. M., J. Boekhorst, T. Abee, R. J. Siezen, and R. Kort. 2013. Complete genome sequence of Anoxybacillus flavithermus TNO-09.006, a thermophilic sporeformer associated with a dairyprocessing environment. Genome Announc. 1:e0010-e0013.

Caspers, M. P. M., J. Boekhorst, A. de Jong, R. Kort, M. Nierop Groot, and T. Abee. 2016. Draft genome sequences of four thermophilic spore formers isolated from a dairy-processing environment. Genome Announc. 4:e00757-16.

de Vos, W. M., and E. E. Vaughan. 1994. Genetics of lactose utilization in lactic acid bacteria. FEMS Microbiol. Rev. 15:217-237.

Enright, A. J., S. Van Dongen, and C. A. Ouzounis. 2002. An efficient algorithm for large-scale detection of protein families. Nucleic Acids Res. 30:1575-1584.

Jensen, R. G. 1995. Introduction. Page 3 in Handbook of Milk Composition. Academic Press, London, UK.

Mitchell, A., H. Y. Chang, L. Daugherty, M. Fraser, S. Hunter, R. Lopez, C. McAnulla, C. McMenamin, G. Nuka, S. Pessear, A. Sangrador-Vegas, M. Scheremetjew, C. Rato, S. Y. Yong, A. Bateman, M. Punta, T. K. Attwood, C. J. Sigrist, N. Redascgu, C. Rivoire, I. Xenarios, D. Kahn, D. Guyot, P. Bork, I. Letunic, J.
Gough, M. Oates, D. Haft, H. Huang, D. A. Natale, C. H. Wu, C. Orengo, I. Sillitoe, H. Mi, P. D. Thomas, and R. D. Finn. The InterPro protein families database: The classification resource after 15 years. Nucleic Acids Res. 43:D213-D221.

Sadiq, F. A., Y. Li, T. Liu, S. Flint, G. Zhang, L. Yuan, Z. Pei, and G. He. 2016. The heat resistance and spoilage potential of aerobic mesophilic and thermophilic spore forming bacteria isolated from Chinese milk powders. Int. J. Food Microbiol. 238:193-201.

Seale, B., S. Burgess, S. Flint, J. Brooks, P. Bremer, and S. Parkar. 2015. Thermophilic spore-forming bacilli in the dairy industry. Pages 112-137 in Biofilms in the Dairy Industry. John Wiley \& Sons Ltd., Chichester, UK.

Setlow, P., and E. A. Johnson. 2013. Spores and their significance. Pages 45-79 in Food Microbiology. ASM Press, Washington, DC.

Tola, Y. B., and H. S. Ramaswamy. 2014. Combined effects of high pressure, moderate heat and $\mathrm{pH}$ on the inactivation kinetics of $\mathrm{Ba}$ cillus licheniformis spores in carrot juice. Food Res. Int. 62:50-58.

Watterson, M. J., D. J. Kent, K. J. Boor, M. Wiedmann, and N. H. Martin. 2014. Evaluation of dairy powder products implicates thermophilic sporeformers as the primary organisms of interest. J. Dairy Sci. 97:2487-2497.

Wells-Bennik, M. H. J., R. T. Eijlander, H. M. W. den Besten, E. M. Berendsen, A. K. Warda, A. O. Krawczyk, M. N. Nierop Groot, Y. Xiao, M. H. Zwietering, O. P. Kuipers, and T. Abee. 2016. Bacterial spores in food: Survival, emergence, and outgrowth. Annu. Rev. Food Sci. Technol. 7:457-482.

Yazdany, S., and K. B. Lashkari. 1975. Effect of $\mathrm{pH}$ on sporulation of Bacillus stearothermophilus. Appl. Microbiol. 30:1-3.

Zhao, Y., M. P. M. Caspers, T. Abee, R. J. Siezen, and R. Kort. 2012. Complete genome sequence of Geobacillus thermoglucosidans TNO-09.020, a thermophilic sporeformer associated with a dairyprocessing environment. J. Bacteriol. 194:4118.

Zhao, Y., M. P. M. Caspers, K. I. Metselaar, P. de Boer, G. Roeselers, R. Moezelaar, M. Nierop Groot, R. C. Montijn, T. Abee, and R. Kort. 2013. Abiotic and microbiotic factors controlling biofilm formation by thermophilic sporeformers. Appl. Environ. Microbiol. 79:5652-5660. 